\title{
Visualization of energy flows in PVT systems
}

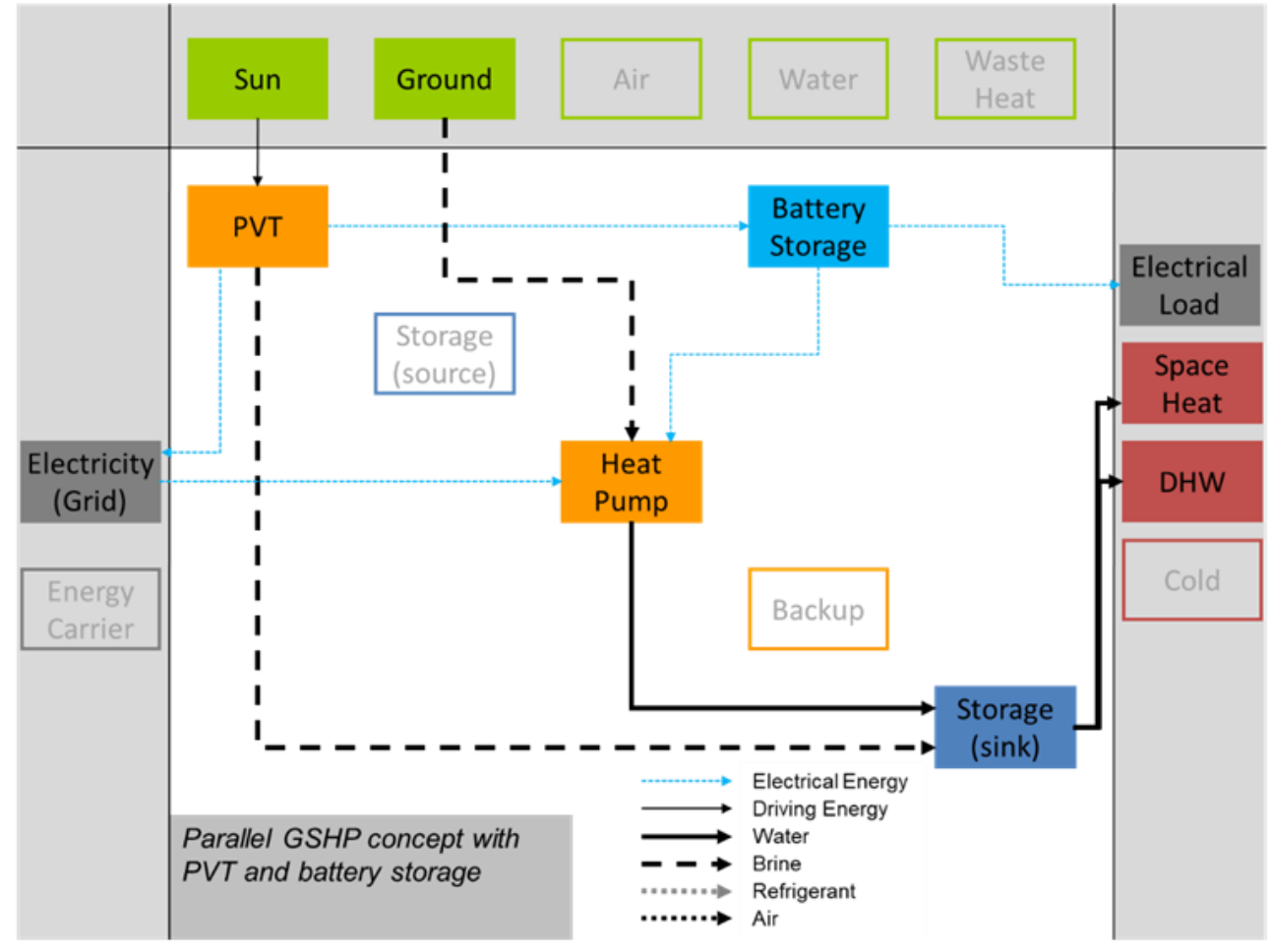




\title{
Visualization of energy flows in PVT systems
}

\author{
SHC Task 60/Report D4
}

\section{A visualization scheme for the uniform representation of combined electrical and thermal energy flows in PVT systems}

\author{
Danny Jonas \\ Date: 10.05.2019 \\ Report number D4 of Task 60 \\ DOI: 10.18777/ieashc-task60-2019-0001
}




\section{Contents}

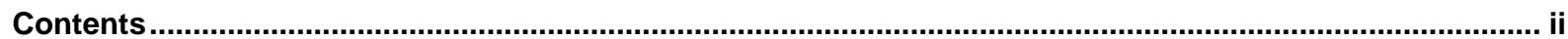

1 Interaction in systems and visualization of energy flows...............................................................

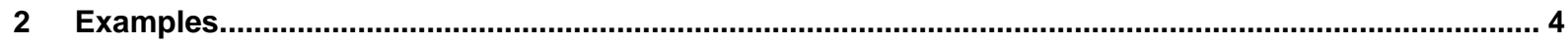

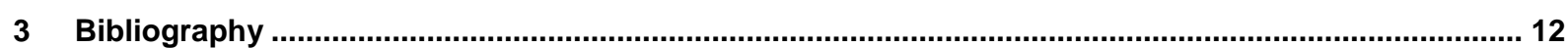




\section{Interaction in systems and visualization of energy flows}

PVT collectors are always part of a system approach. These kinds of systems are highly integrated. So, all components have to interact with each other in a well-concerted way and it is important to describe this in a technical way that incorporates different information needed for the interaction. One possibility to describe the interaction of PVT collectors and other components in a system is the use of a representation of flows developed in an IEA SHC Task (Task 44 - see ref). The representation is called the "energy flow diagram" or simply "square views" (you will understand why) for the visualization of energy flows between the different system components.

The approach, which will be presented in this report, can be used for thermal as well as for electrical system concepts, and especially the interaction of the thermal and electrical parts in PVT concepts. The main advantage of this method is the simple and structured way to describe the functionality of a system and the interaction of its components, especially with regard to their energy flows. It allows a better comparability and fast understanding of a whole system and avoids misunderstanding of functionality. Furthermore, system developers / manufacturers can easily describe their new products and make them comparable with existing solutions and customers or engineers can identify system features and applications at a glance. Especially in complex thermal and electrical systems with PVT, the method shows the level of system integration of the PVT collectors and whether it is part of a whole system approach or a side-by-side installation without high level of integration. In addition, the method offers a possibility to define detailed system and component boundaries for the definition of key performance indicators that is also an important aspect to increase the comparability of systems and its analyses.

Basically, the representation is based on the work of Frank et al. (2010) and IEA SHC Task 44 / HPP Annex 38 and what is described in the present document can be seen as an enhancement of Task 44 work for electrical systems not part of the original concept. The visualization is very similar to other energy flow charts, but with fixed boundaries, positions and colors as well as defined connection line styles. In general, the system boundaries like final energy which has to be purchased, useful energy like space heating, or environmental energy sources like the sun, as well as different system components like a heat pump, PVT collectors or a storage, are shown at given places and are highlighted with given colors if they exist in the system concept (cf. Fig. 1).

For the system components, the following given elements are defined and can be highlighted if they exist in the concept:

(1) Solar energy converters like PVT and solar thermal collectors or absorbers (or PV)

(2) Thermal storages on the source side of the heat pump

(3) Heat pump

(4) Backup heater like conventional boiler or heating rod

(5) Thermal storages on the sink side of the heat pump

(6) Electrical (battery) storages.

All these components are displayed via placeholders. If a component is not used, it is also shown but without highlighting. Furthermore, three different system boundaries are defined:

- Left boundary: Final energy, which has to be purchased, e.g. gas or electricity (grid)

- Right boundary: Useful energy, e.g. for DHW preparation or space heating, and (final) electrical energy consumption / load (except the electrical energy consumption of the system), e.g. residential electricity load for lighting, cooking, etc.

- Upper boundary: Environmental energy sources, e.g. sun, ambient air or ground

Within the system boundaries, the different elements are also highlighted if they exist / are used in the concept (cf.

Fig. 1). 

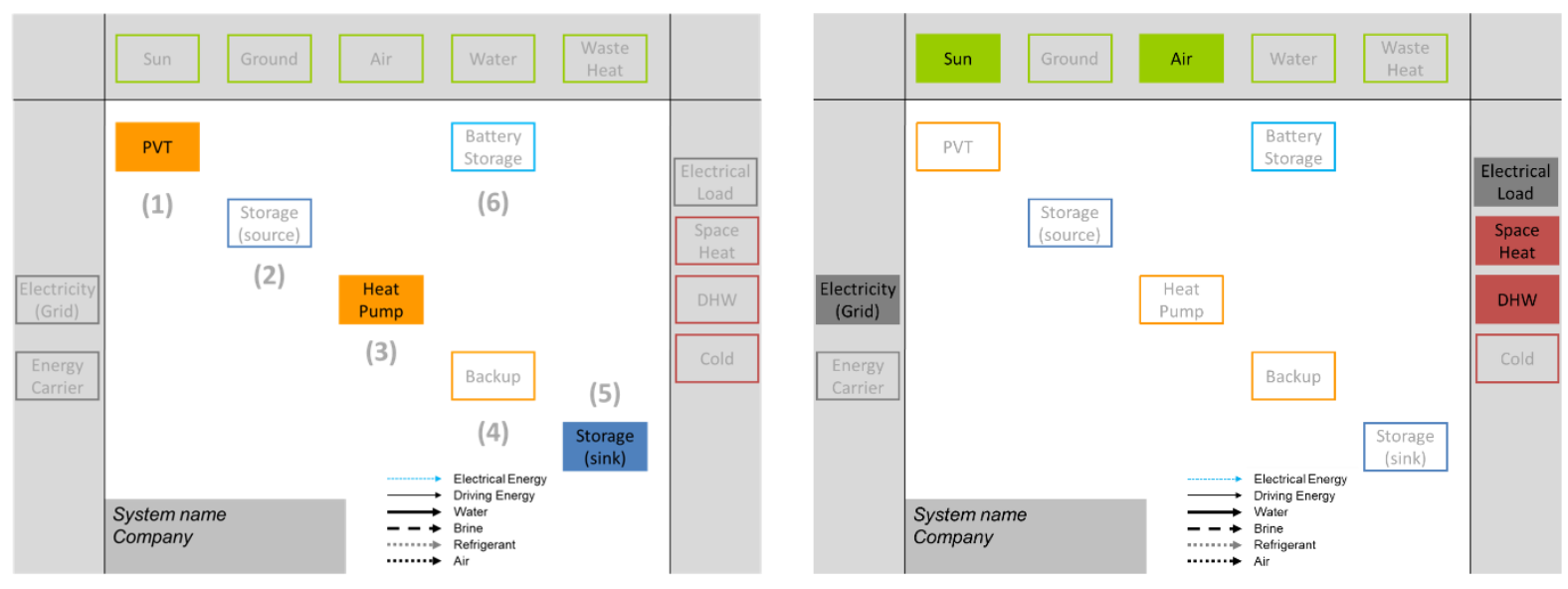

Fig. 1: System "square view" components (highlighted left) and boundaries (highlighted right)

To differentiate system components and boundaries, the following colors are used:

- Energy Converters: Orange

- Thermal storages: Blue

- Electrical storages: Light Blue (color also used for electrical energy flows)

- Final Energy: Grey

- Environmental Energy: Green

- Useful Energy: Red

The system components are connected among themselves and with the boundaries via lines to depict the energy flows in the system. As shown in Fig. 2, six different line styles are used for the indication of:

- different energy carrier mediums (water, brine, refrigerant or air)

- electrical energy or

- $\quad$ other driving energies (e.g. solar irradiation or gas).

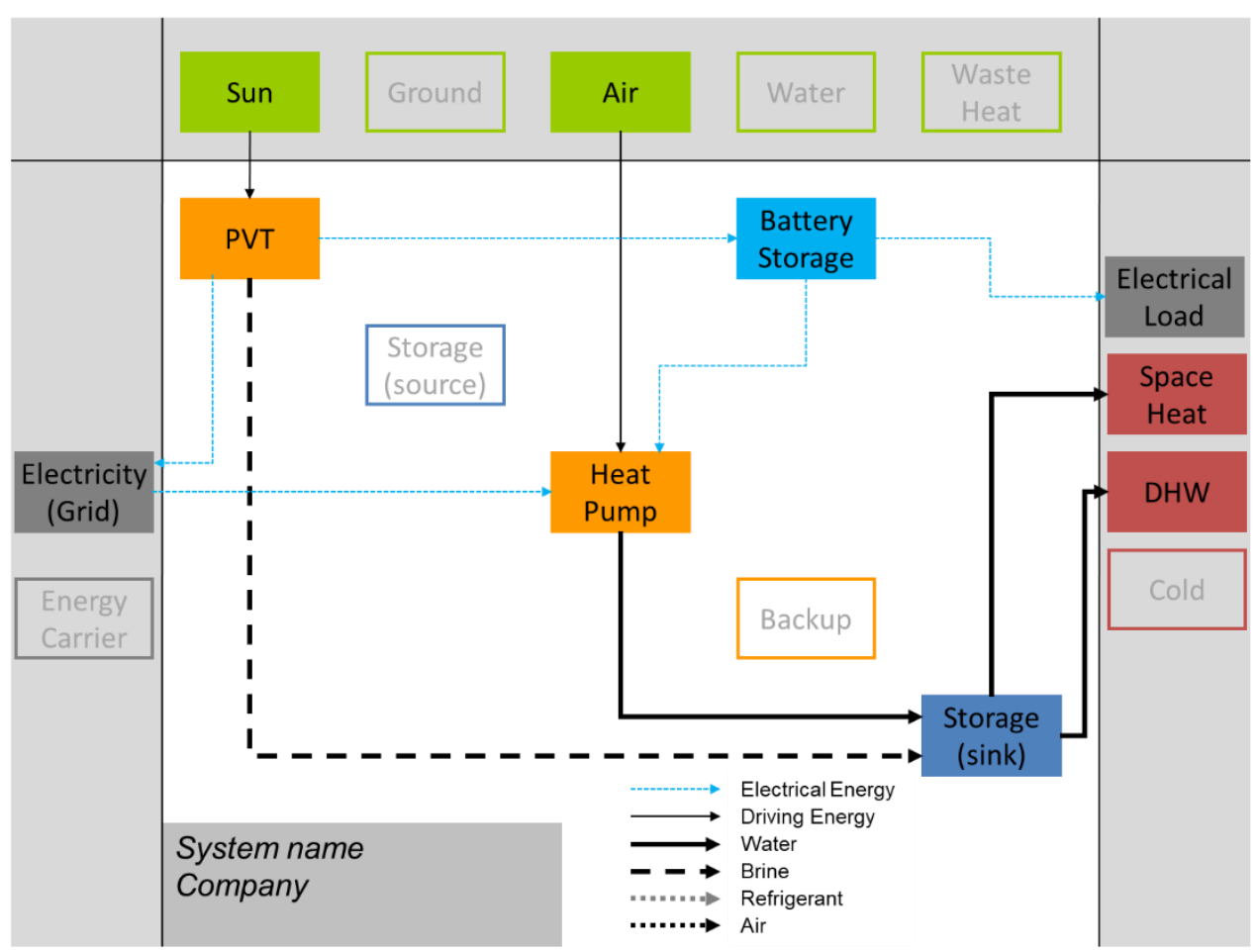

Fig. 2: System square view connections 
For the complete description of a system concept with the so-called "square views", the following steps need to be performed:

(1) Highlighting of existing system components

(2) Highlighting of used environmental energy sources

(3) Highlighting of final energy which has to be purchased

(4) Highlighting of existing electrical energy consumptions and useful energy demands

(5) Connection of the components of the system among themselves and with the boundaries with indication of the carrier medium / driving energy. 


\section{Examples}

Examples for the visualization of typical PVT applications and systems are shown in the following figures.

Example 1: Parallel air source heat pump system concept with PVT and battery storage

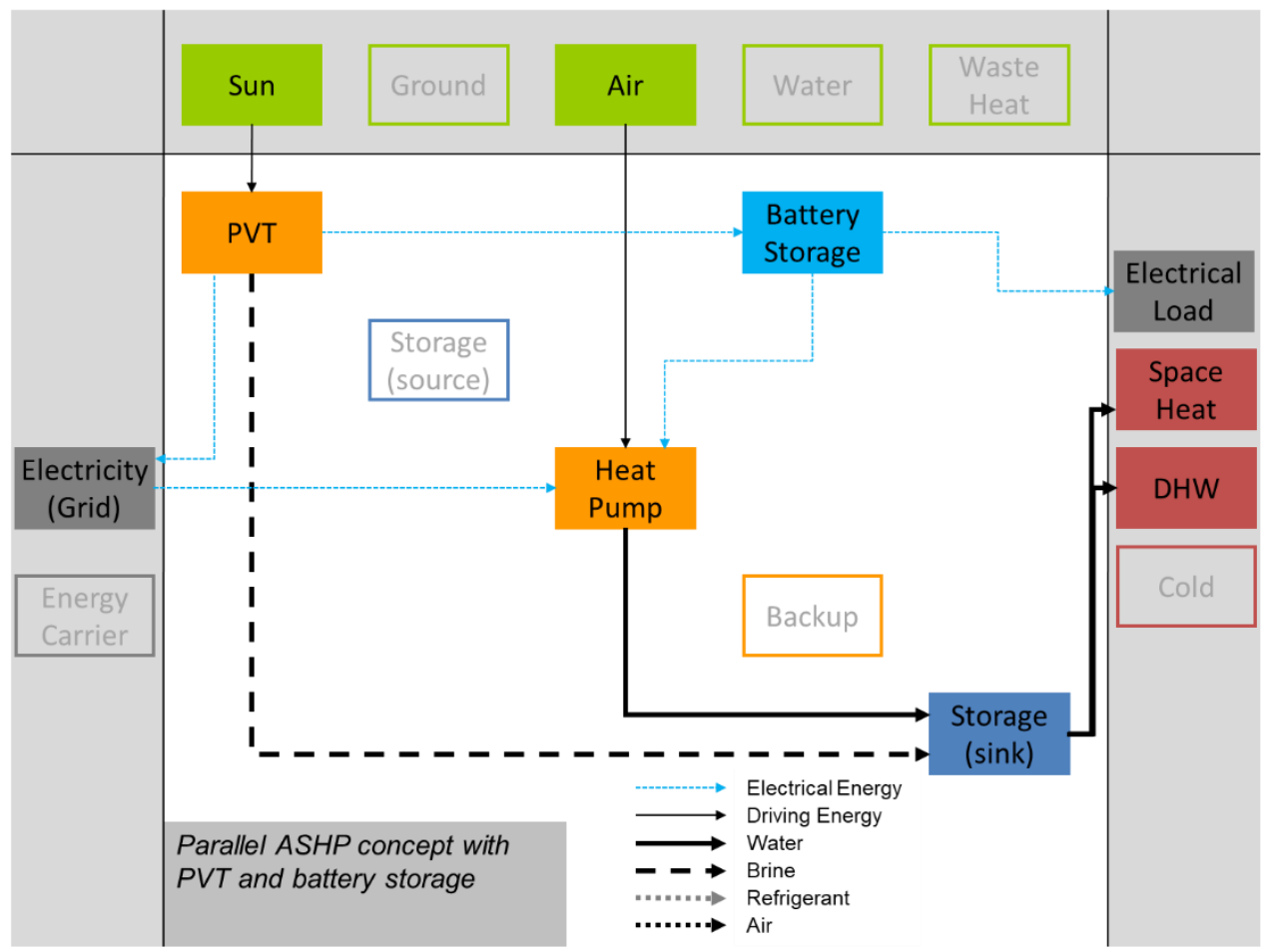

Example 2: Parallel ground source heat pump system concept with PVT and battery storage

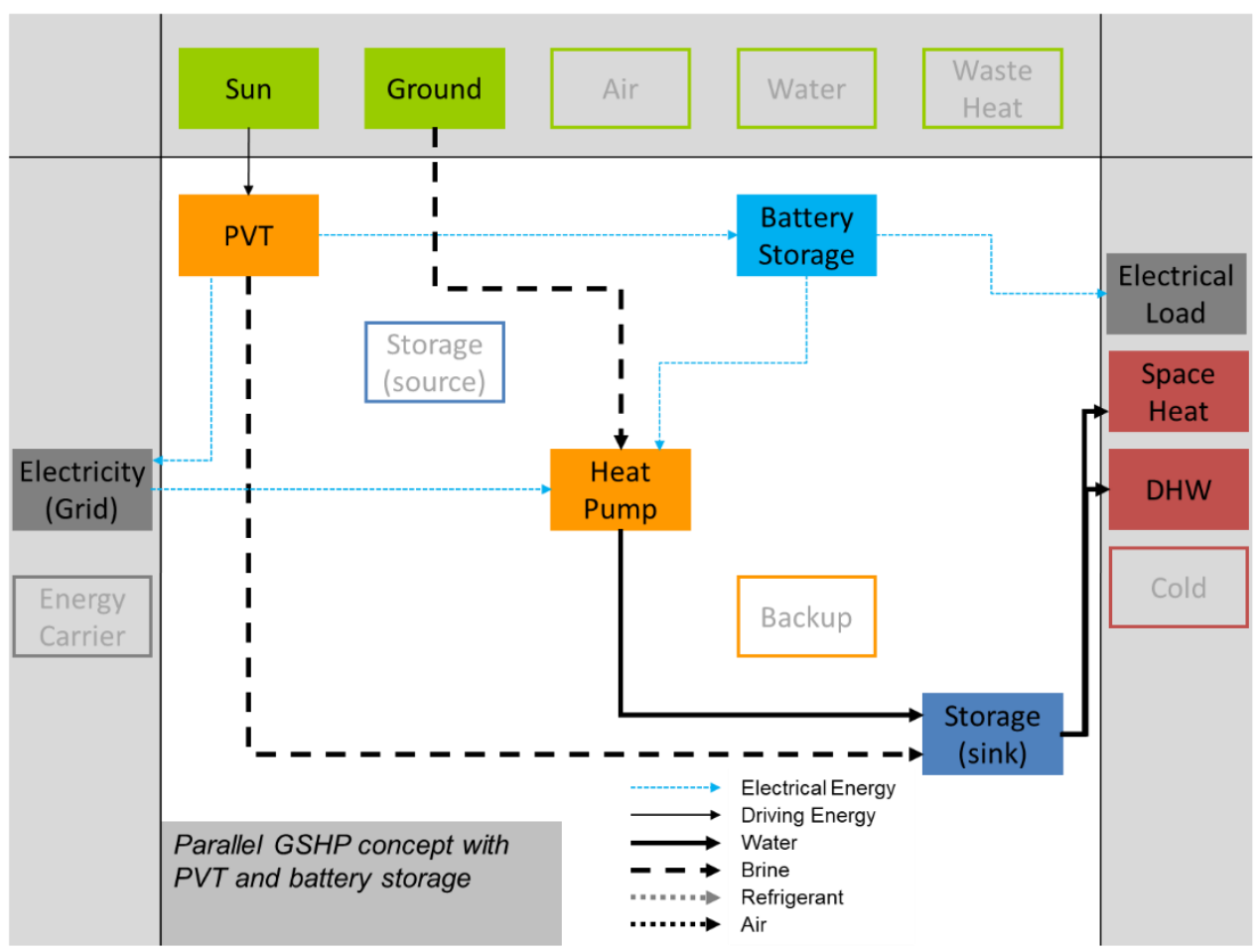


Example 3: Parallel ground source heat pump system concept with PVT, separated DHW (supplied by PVT in parallel) and space heating storage and battery storage

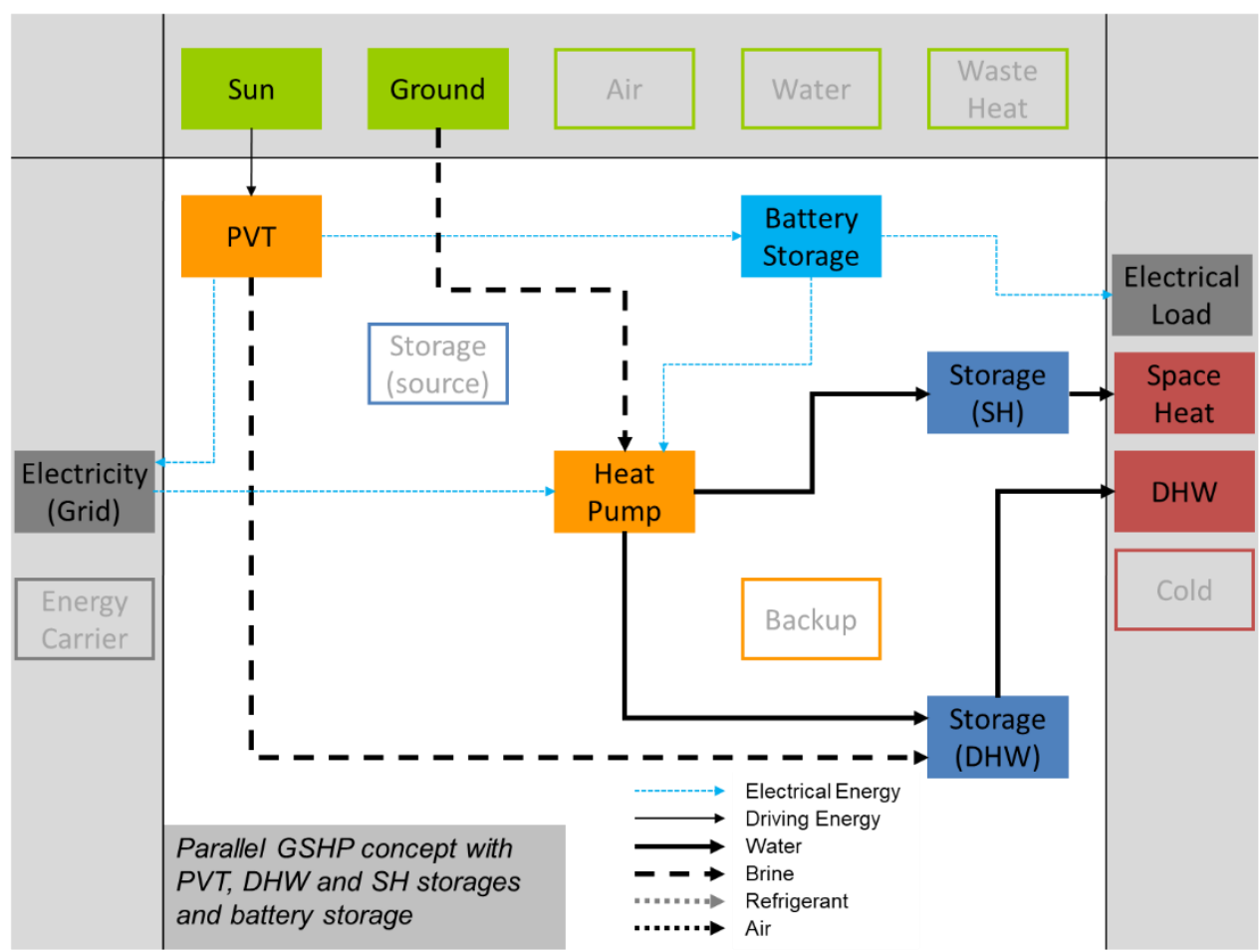

Example 4: Parallel air source heat pump system concept with PVT, electrical heating rod and battery storage

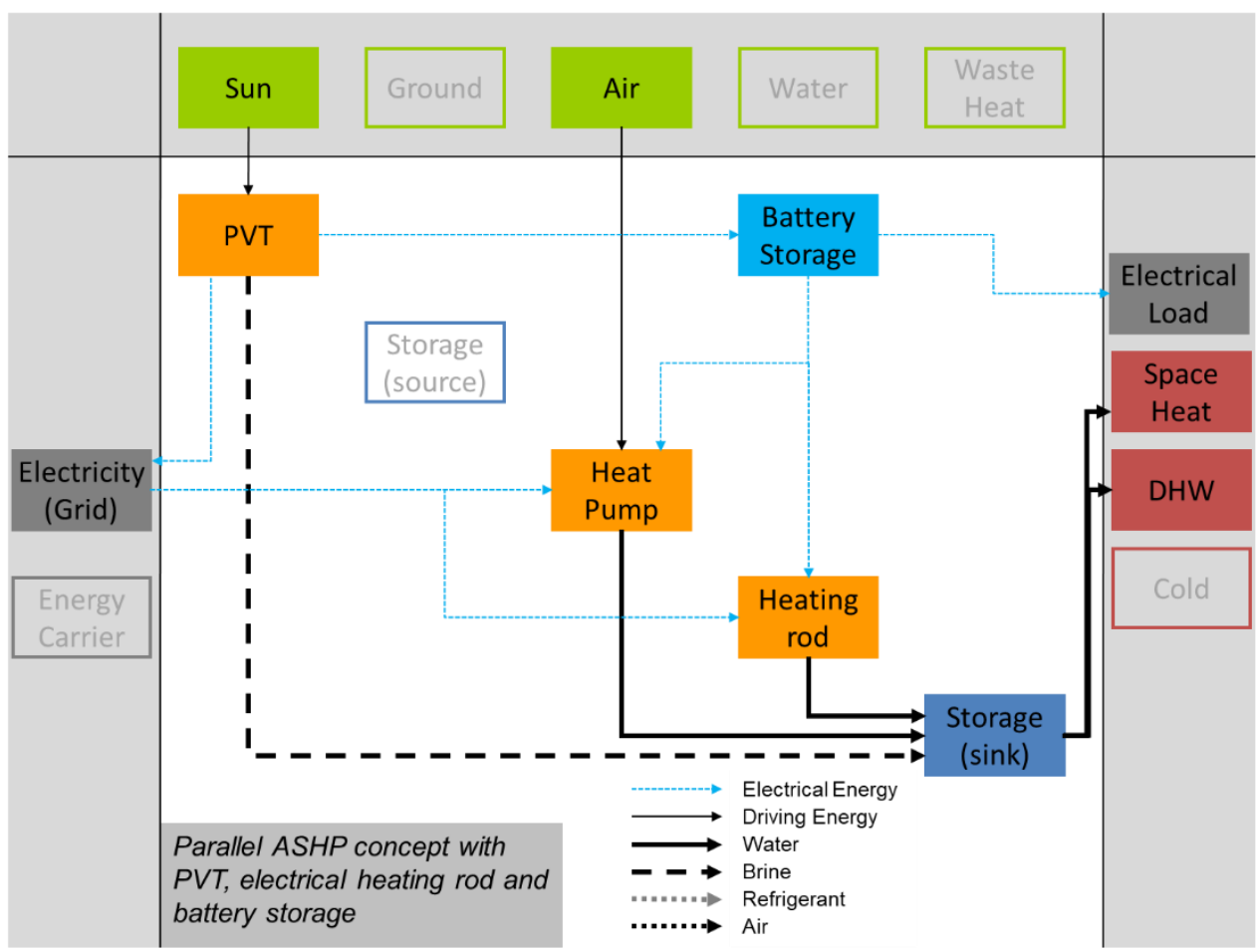


Example 5: Parallel and serial ground source heat pump system concept with PVT and battery storage

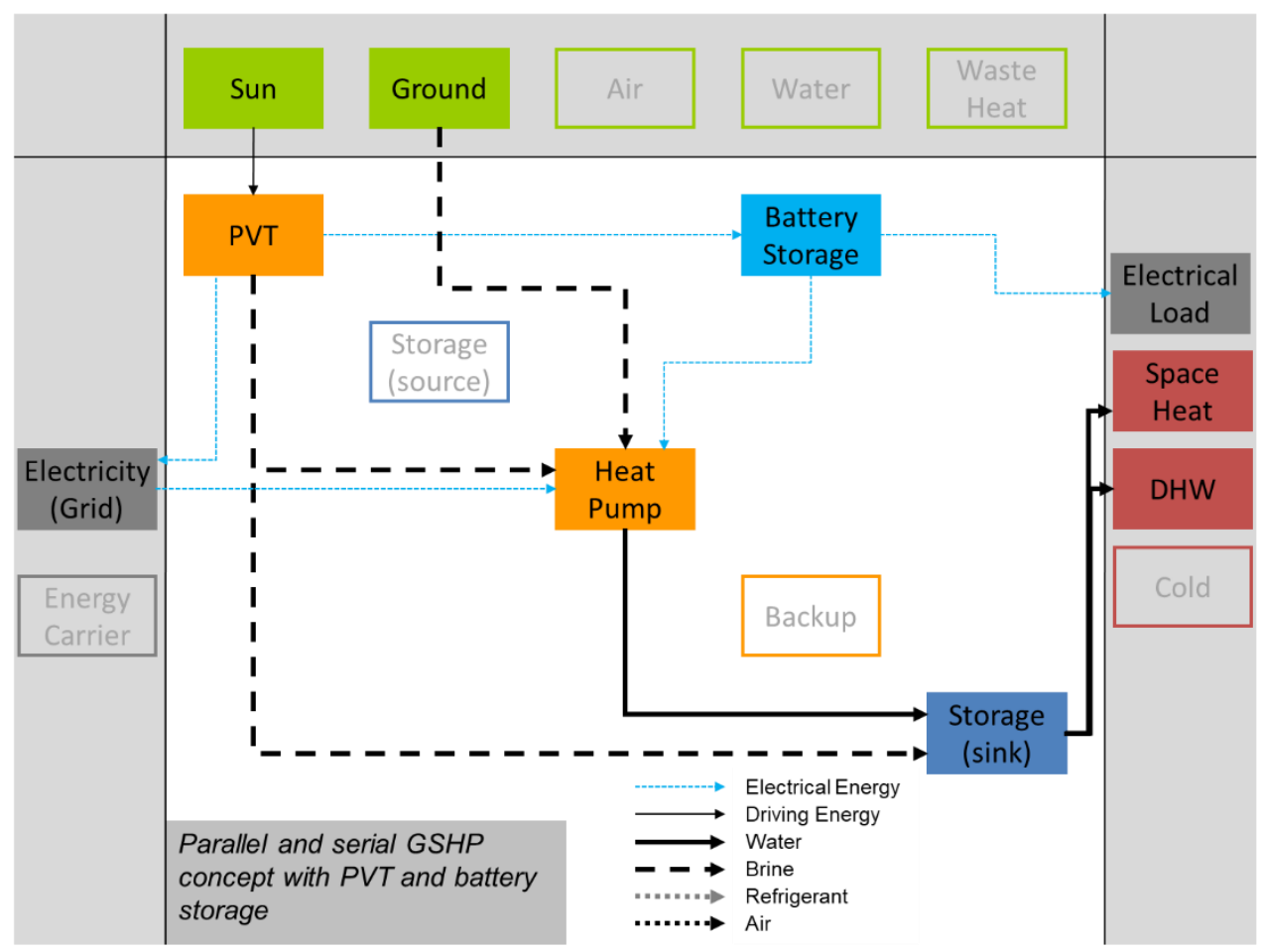

Example 6: Parallel and serial system concept with dual source (air and PVT) heat pump, PVT and battery storage

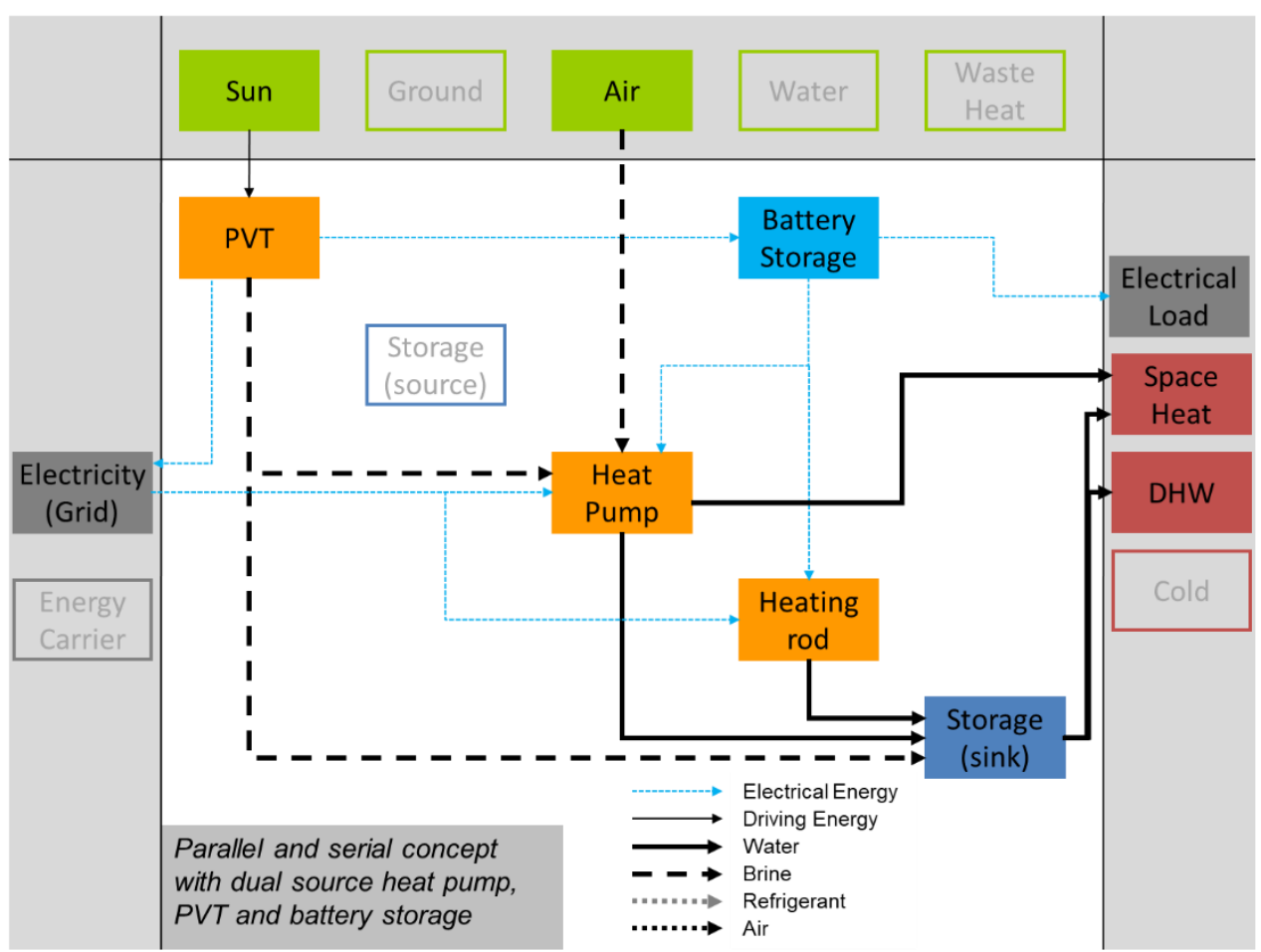


Example 7: Serial system concept with cold side storage as exclusive heat source of the heat pump, PVT and battery storage

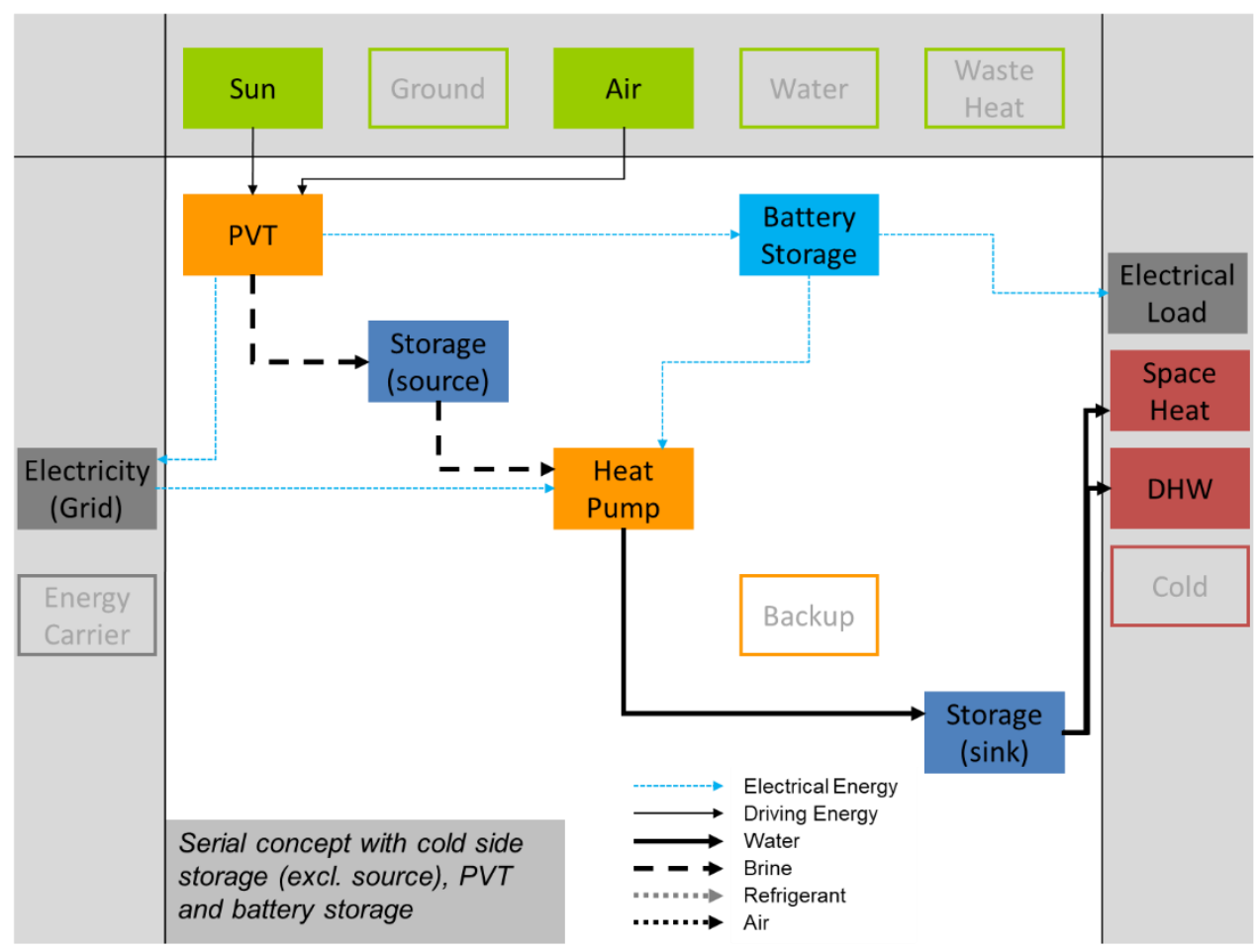

Example 8: Serial system concept with cold side storage as non-exclusive heat source of the heat pump, PVT and battery storage

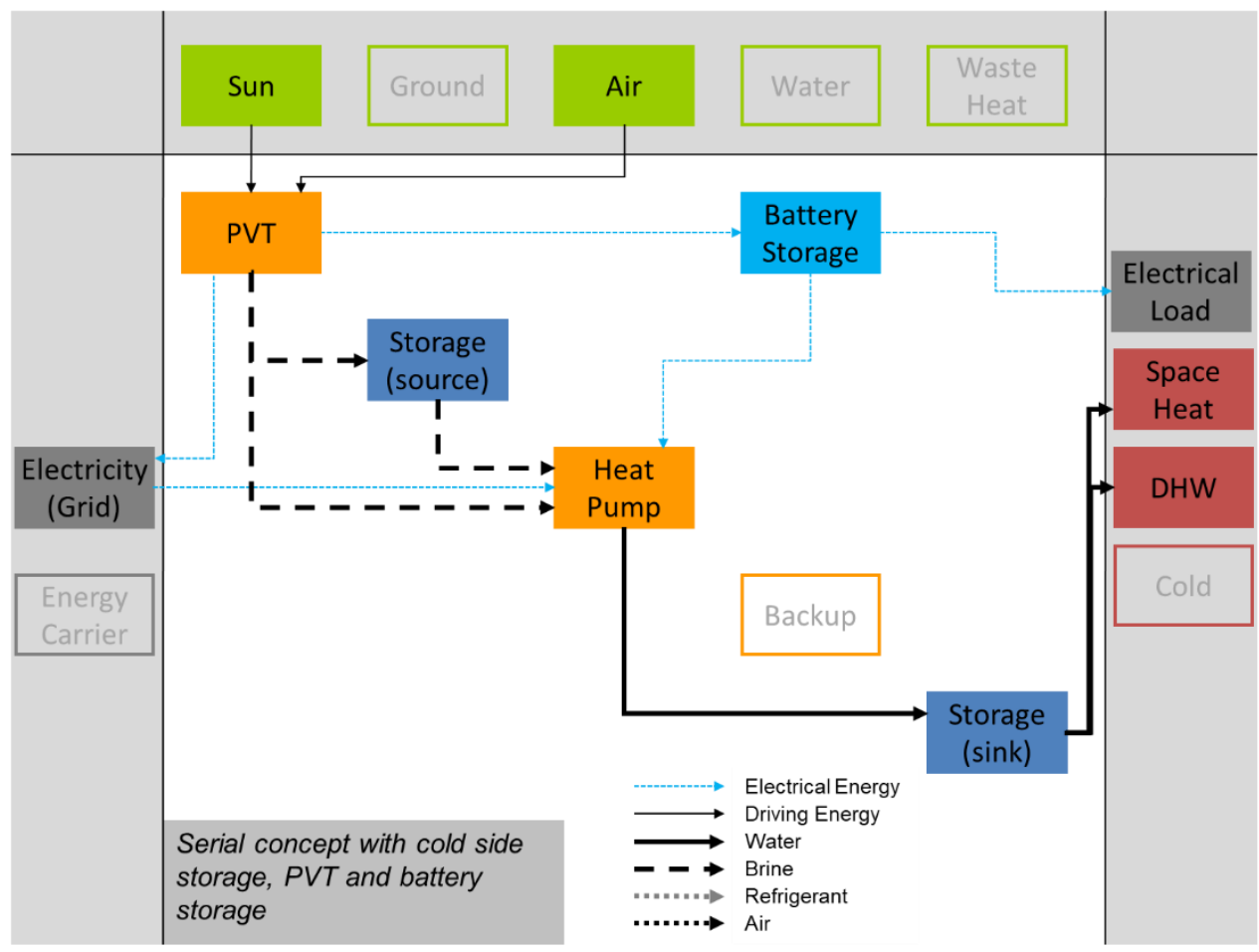


Example 9: Parallel and serial system concept with cold side storage as exclusive heat source of the heat pump, PVT and battery storage

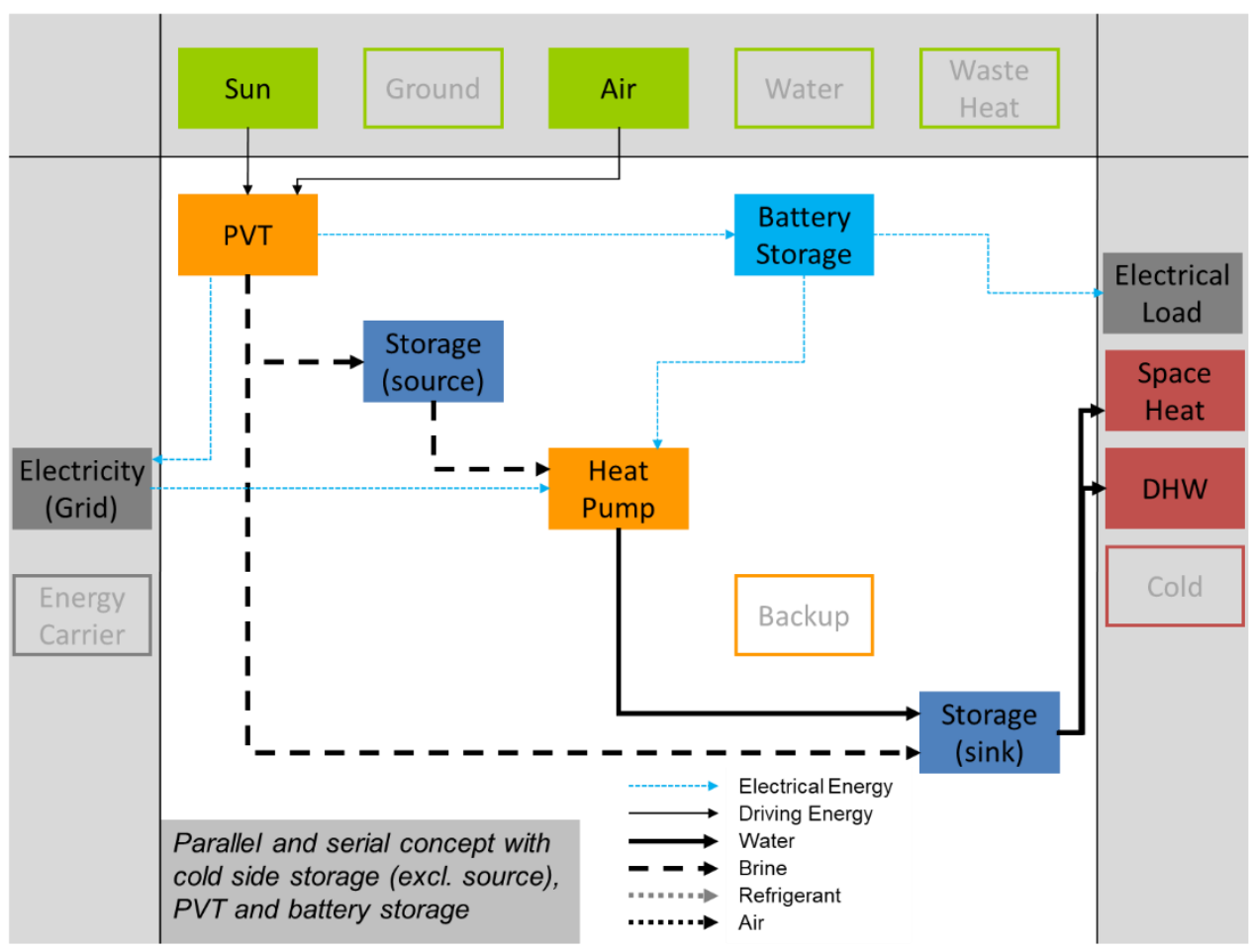

Example 10: Parallel and serial system concept with cold side storage as non-exclusive heat source of the heat pump, PVT and battery storage

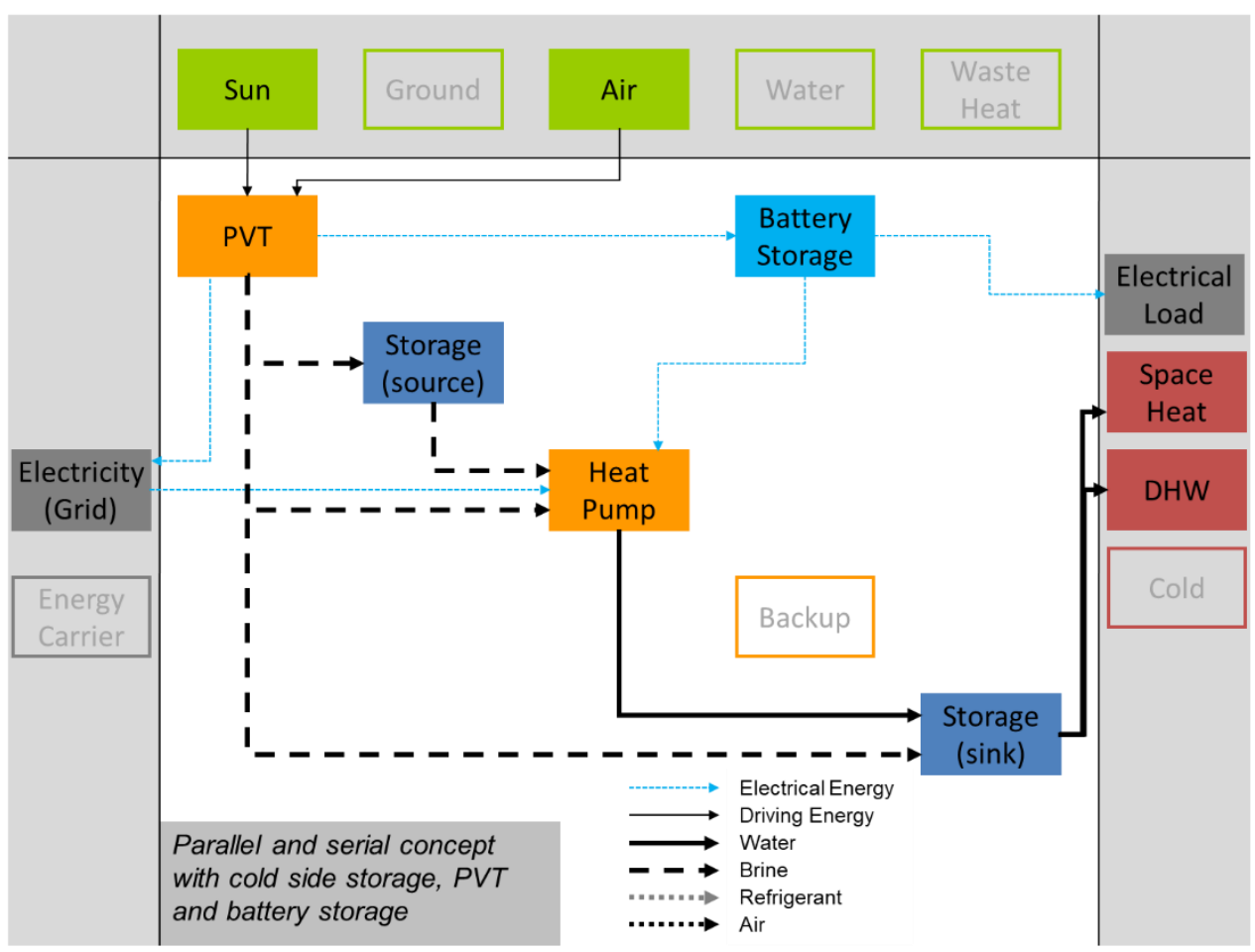


Example 11: Serial and regenerative ground source heat pump system concept with PVT and battery storage

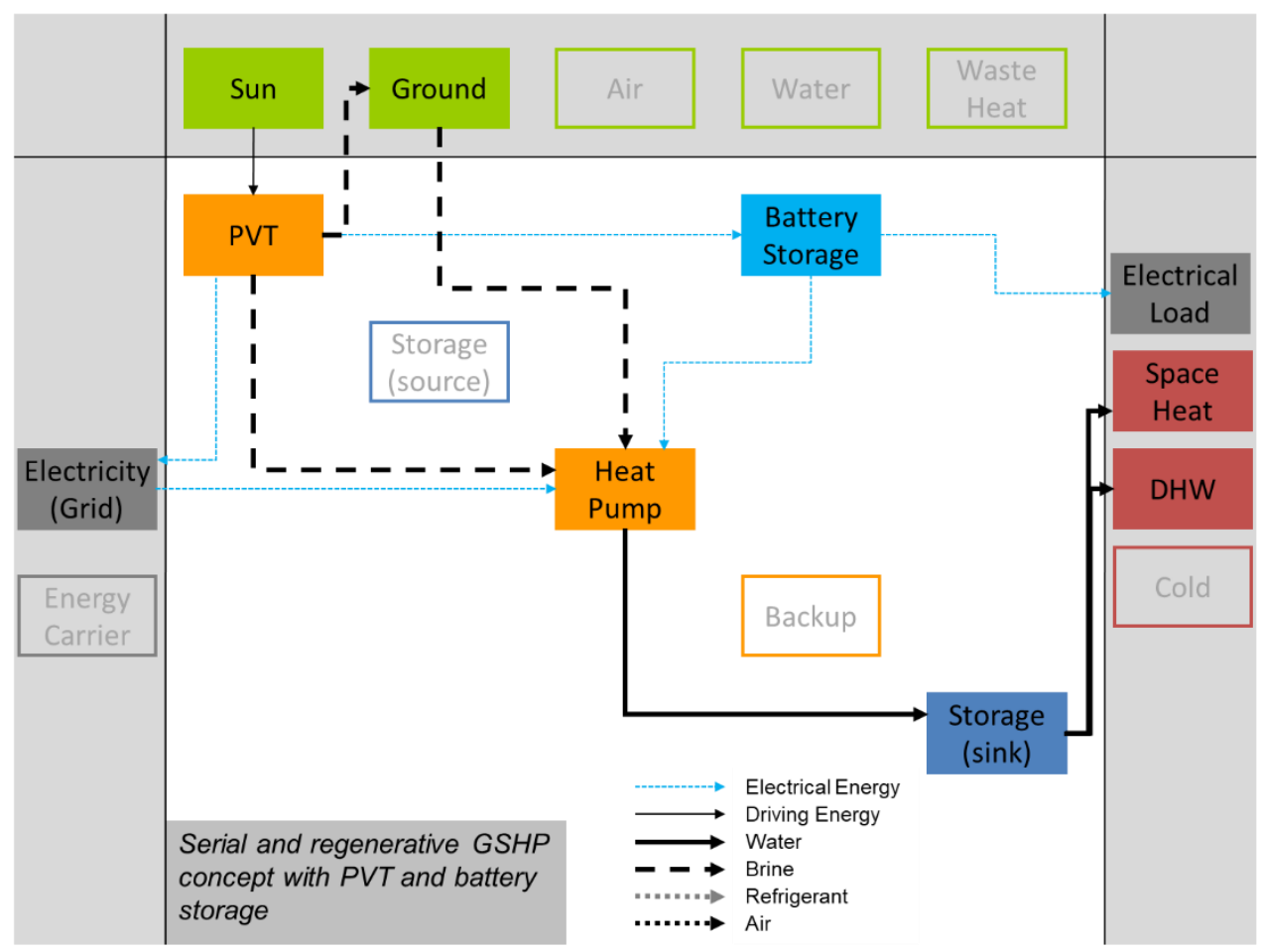

Example 12: Parallel, serial and regenerative ground source heat pump system concept with PVT and battery storage

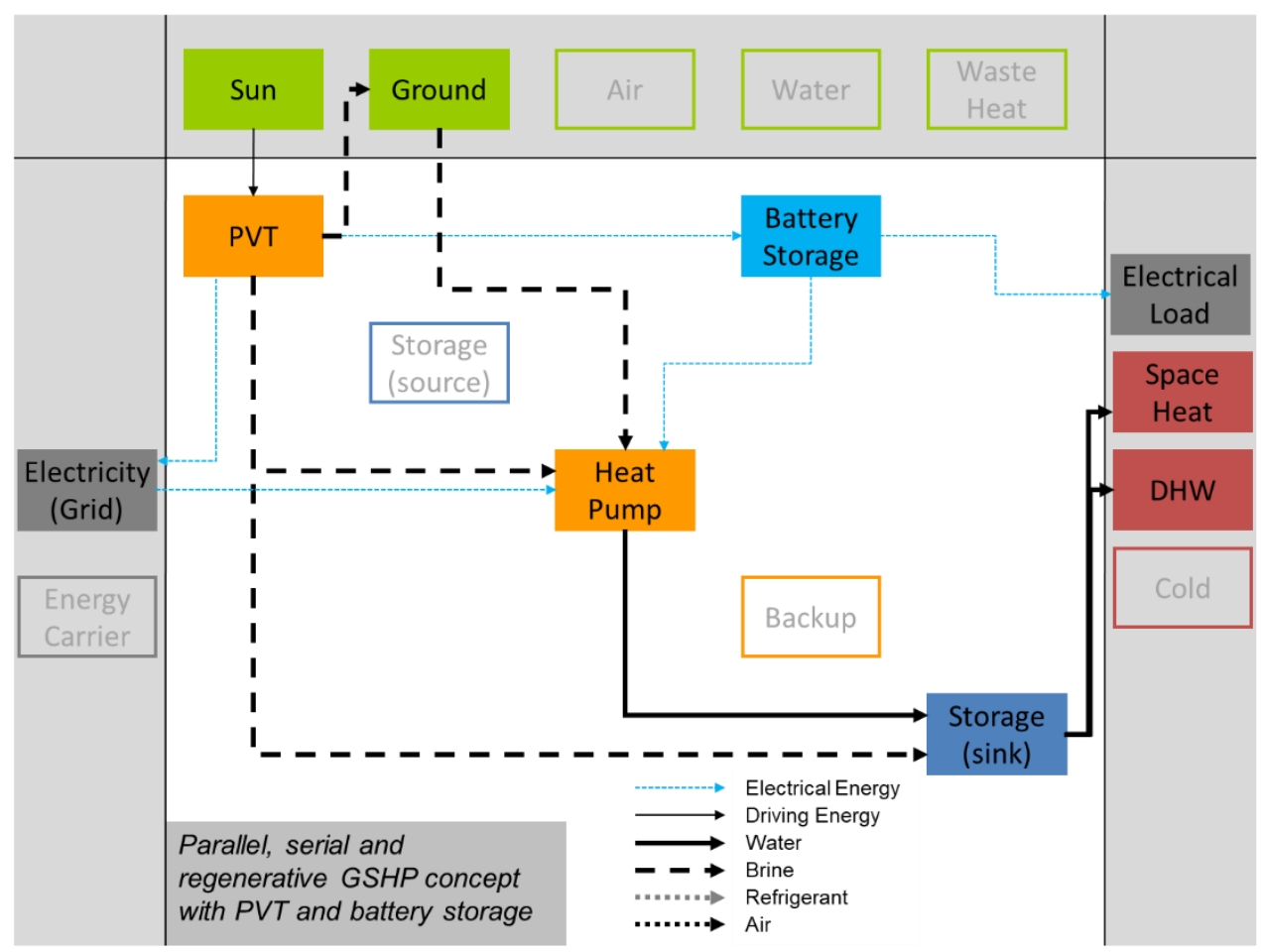


Example 13: Solar thermal heating system with PVT, gas boiler and battery storage

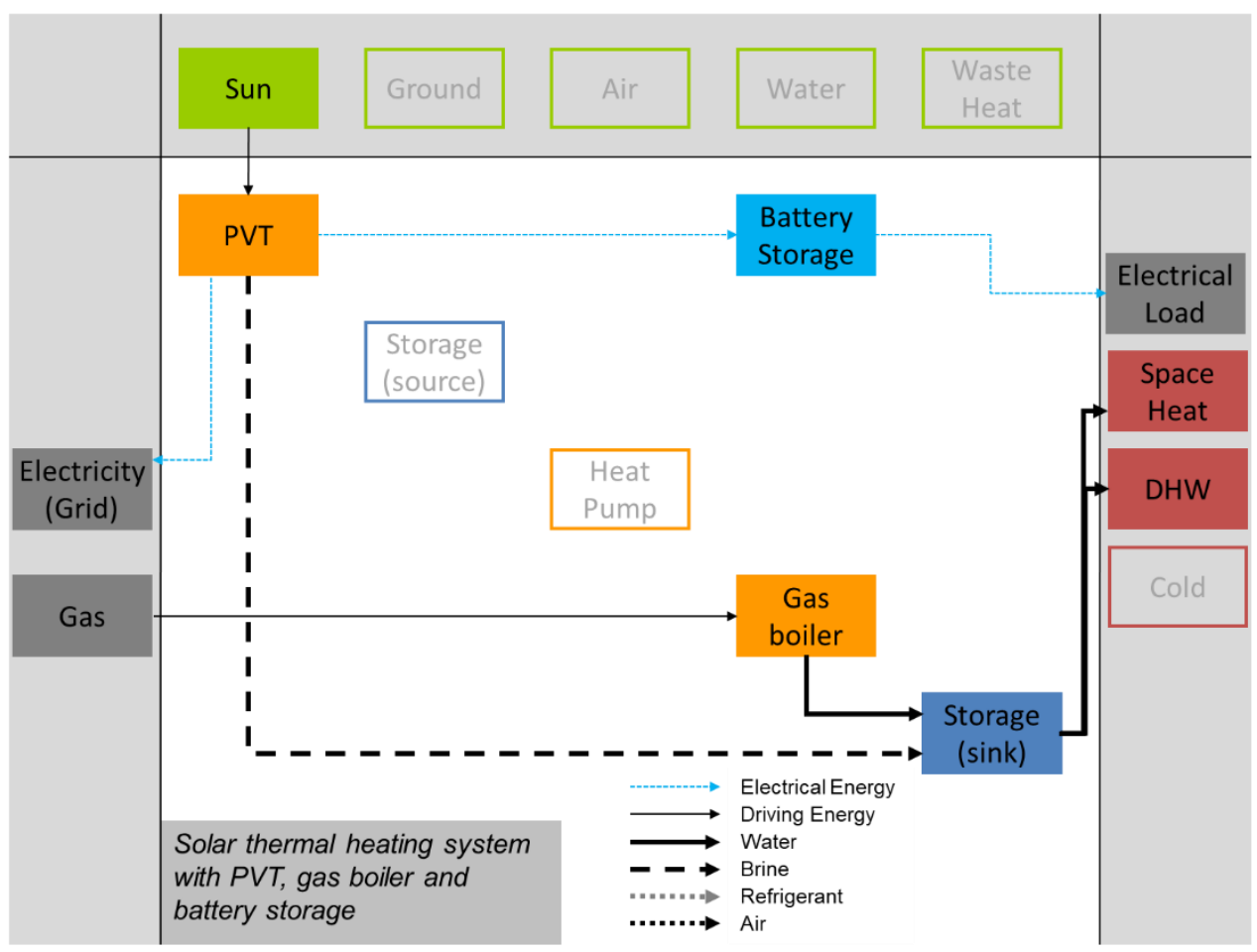

Example 14: Air conditioning system with PVT, electrical heating rod for DHW and battery storage

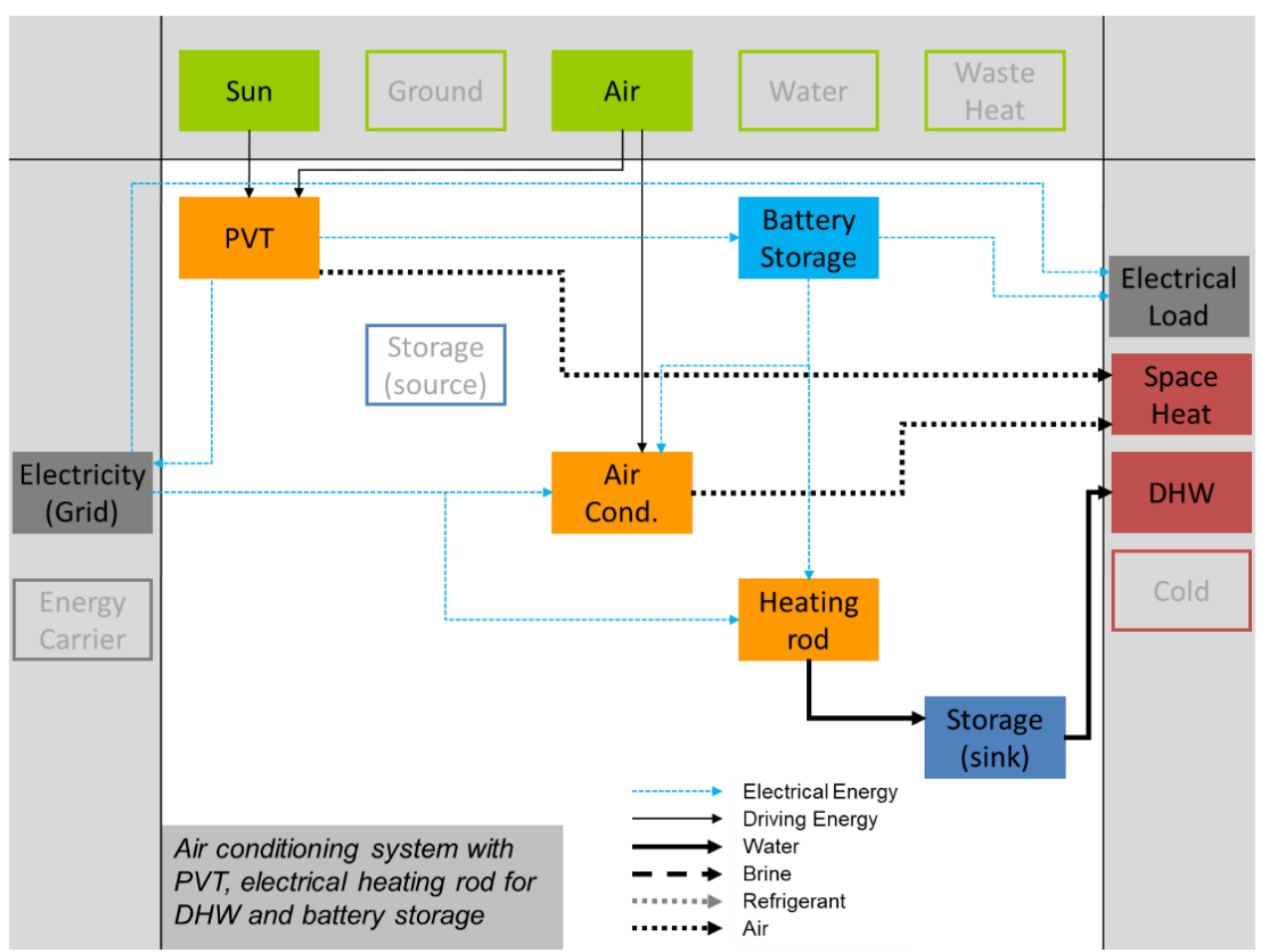


Example 15: Air conditioning system with PV and PVT and electrical heating rod for DHW

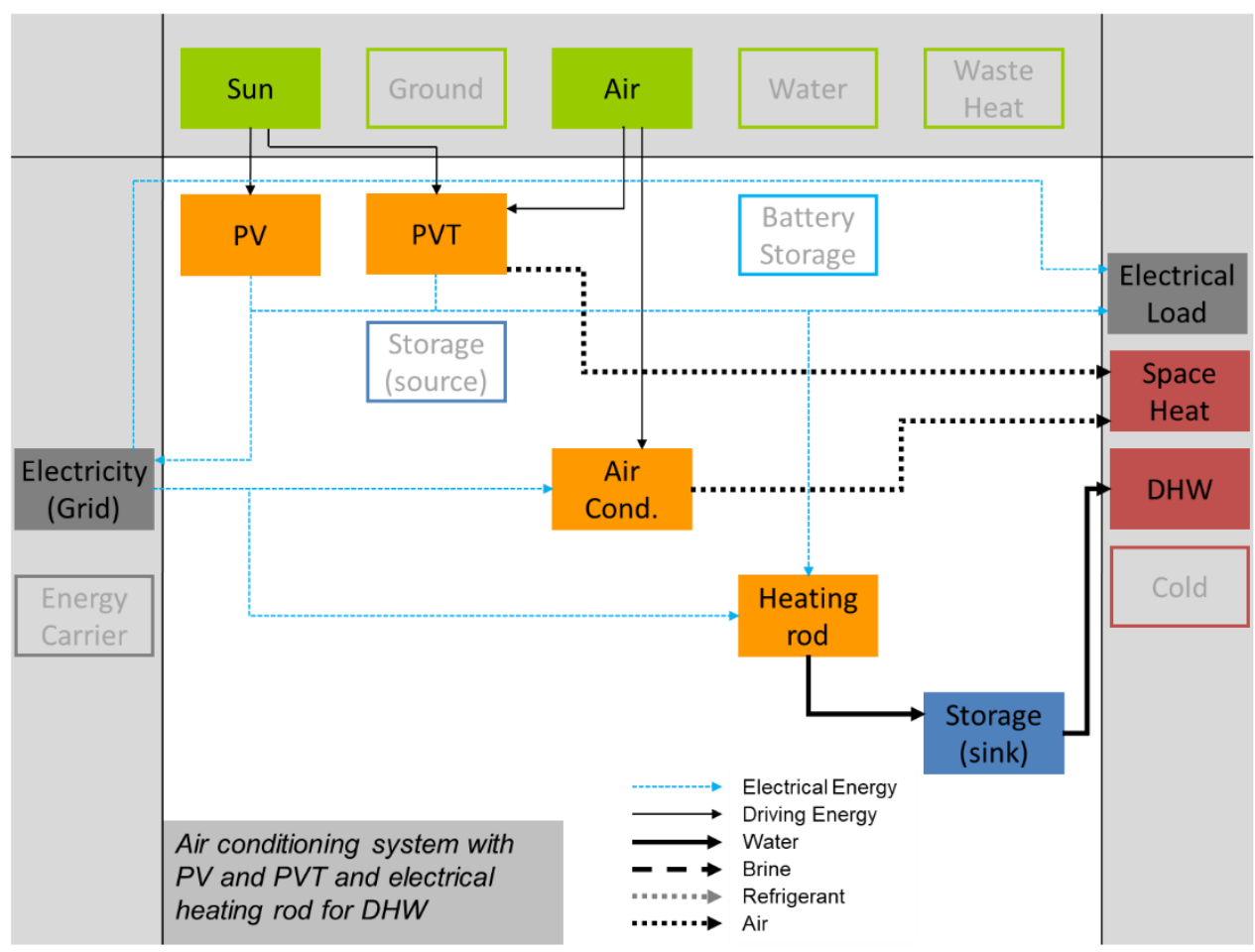




\section{Bibliography}

Frank, E., Haller, M., Herkel, S., Ruschenburg, J., 2010. Systematic classification of combined solar thermal and heat pump systems. In: Proceedings of the of the EuroSun 2010 Conference, Graz, Austria. DOI: 10.13140/2.1.3838.6883 